\title{
PERBANDINGAN NILAI DAYA DUKUNG FONDASI DANGKAL MENURUT METODE TERZAGHI DAN MEYERHOF
}

\section{COMPARISON OF SHALLOW FOUNDATION SUPPORTING CAPACITY BY TERZAGHI AND MEYERHOF METHOD}

\author{
Hisam Asngari ${ }^{*}$, Suradji Gandi², Fatma Sarie $^{3}$ \\ ${ }^{1}$ Mahasiswa / Program Studi Teknik Sipil / Fakultas Teknik / Universitas Palangka Raya \\ ${ }^{2,3}$ Dosen / Program Studi Teknik Sipil / Fakultas Teknik / Universitas Palangka Raya \\ *Korespondensi: hisam.asngari77@gmail.com
}

\begin{abstract}
ABSTRAK
Bangunan memerlukan fondasi sebagai dasar bangunan yang kuat dan kokoh. Fondasi bertujuan sebagai penopang bangunan dan meneruskan beban bangunan di atasnya ke lapisan tanah yang cukup kuat daya dukungnya. Untuk menghitung daya dukung tanah terdapat banyak rumus yang dapat digunakan. Hasil masing-masing rumus tersebut menghasilkan nilai daya dukung yang berbeda-beda. Tujuan studi ini untuk menghitung dan menganalisis daya dukung fondasi dangkal dari hasil hand boring dengan metode Terzaghi dan Meyerhof. Hasil penelitian menunjukan, bahwa daya dukung tanah fondasi dangkal metode Terzaghi lebih kecil dari pada metode Meyerhof. Dengan nilai dari metode terzaghi yaitu 353,443 KN/m², sedangkan metode Meyerhof mengalami kenaikan sebesar 70,094\%, dengan nilai yaitu sebesar $601,185 \mathrm{KN} / \mathrm{m}^{2}$.
\end{abstract}

\section{Kata Kunci: Analasis, Daya Dukung, Fondasi Dangkal, Tanah}

\section{ABSTRACT}

In every building, a foundation is needed as a strong and sturdy building foundation. The foundation aims to support the building and pass the load on the building above it to a layer of soil that is strong enough to have a bearing capacity. To calculate the carrying capacity of the soil, there are many formulas that can be used. The results of each of these formulas produce different carrying capacity values. The purpose of this study is to calculate and analyze the bearing capacity of shallow foundations from the results of hand boring with the Terzaghi and Meyerhof methods. The results showed that the carrying capacity of the shallow foundation soil in the Terzaghi method was smaller than that of the Meyerhof method. The value of the terzaghi method is $353,443 \mathrm{KN} / \mathrm{m}^{2}$, while the Meyerhof method has increased by $70,094 \%$, with a value of $601,185 \mathrm{KN} / \mathrm{m}^{2}$.

Keywords: Analysis, Carrying Capacity, Shallow Foundatio, Soil

\section{PENDAHULUAN}

\section{Latar Belakang}

Daya dukung tanah merupakan salah satu faktor yang penting dalam perencanaan sebuah struktur pembangunan. Tanah yang berada di bawah suatu struktur harus dapat memikul beban yang ada di atasnya tanpa mengalami kegagalan geser (shear failure) dan dengan penurunan (settlement) yang dapat ditolerir.

Dalam menghitung daya dukung tanah terdapat banyak rumus yang dapat di gunakan, diantaranya adalah metode Terzaghi dan Meyerhof. Kedua 
metode tersebut mempunyai rumusan yang berbeda dan anggapan yang berbeda juga.

Tanah yang berada di Kelurahan Pahandut Sebrang, Kota Palangka Raya pada penelitian ini di ambil dengan cara penyelidikan hand boring.

Pada penelitian ini akan dilakukan apakah daya dukung tanah fondasi dangkal dengan metode yang berbeda akan menghasilkan nilai daya dukung yang hampir sama atau sangat berbeda. Kemudian melakukan analisis daya dukung tanah fondasi dangkal pada kasus yang sama berdasarkan metode Terzaghi dan Meyerhof.

\section{KAJIAN PUSTAKA}

\section{Fondasi Dangkal}

Fondasi dangkal (shallow foundation), yaitu jika kedalaman fondasi kurang atau sama dengan lebar fondasi $(\mathrm{D} \leq \mathrm{B})$. Fondasi dangkal ini berupa fondasi telapak, fondasi menerus maupun lingkaran. Fondasi dangkal diartikan sebagai fondasi yang hanya mampu menerima beban relatif kecil dan secara langsung menerima beban bangunan.

\section{Analisis Daya Dukung Terzaghi}

Penyelesaian daya dukung awal diperkirakan dengan asumsi kejadian tanah sebagai keruntuhan geser umum (Terzaghi 1943). Metode Terzaghi dapat diterapkan pada fondasi telapak/lajur yang dipasang pada atau di sekitar permukaan tanah dasar dengan kedalaman fondasi (Df) kurang dari lebar minimum (B).

Berikut merupakan persamaan umum dari teori Terzaghi:

$$
\begin{aligned}
\mathrm{qu}=\mathrm{c} \mathrm{Nc}+\mathrm{q}^{\prime} \mathrm{Nq}+0.5 . \mathrm{B} . \mathrm{N} \gamma \\
q u=\text { daya dukung ultimit }\left(\mathrm{kg} / \mathrm{cm}^{2}\right) \\
c \quad=\text { kohesi tanah }\left(\mathrm{kg} / \mathrm{cm}^{2}\right) \\
\text { Df }=\text { kedalaman fondasi }(\mathrm{m}), \\
B \quad=\text { lebar fondasi }(\mathrm{m}) \\
\gamma \quad=\text { berat volume tanah }\left(\mathrm{kg} / \mathrm{cm}^{3}\right) \\
N c, N q, N \gamma=\text { faktor daya dukung Terzaghi }
\end{aligned}
$$

Nilai-nilai faktor daya dukung Terzaghi Nc, Nq, $\mathrm{N} \gamma$ fungsi dari besarnya besarnya sudut geser dalam $(\phi)$. Untuk pengaruh bentuk fondasi, Terzaghi (1943) dalam Martini (2009) memberikan pengaruh faktor bentuk terhadap daya dukung ultimit yang didasarkan pada analisis fondasi memanjang sebagai berikut:

1. Fondasi bujur sangkar: $\mathrm{qu}=1,3 \mathrm{c} \mathrm{Nc}+\mathrm{q} \cdot \mathrm{Nq}+0,4 \gamma$ B.N $\gamma$

2. Fondasi memanjang:

$\mathrm{qu}=\mathrm{c} \mathrm{Nc}+\mathrm{PoNq}+0,5 \gamma \mathrm{B} . \mathrm{N} \gamma$

3. Fondasi lingkaran:

$\mathrm{qu}=1,3 \mathrm{c} \mathrm{Nc}+\mathrm{q} \cdot \mathrm{Nq}+0,3 \gamma \mathrm{B} \cdot \mathrm{N} \gamma$

\section{Analisis daya dukung Meyerhof}

Meyerhof (1963) memberikan persamaan daya dukung dengan mempertimbangkan faktor bentuk $\mathrm{s}_{\mathrm{q}}$, factor kedalaman $\mathrm{d}_{\mathrm{i}}$ dan faktor kemiringan $\mathrm{i}_{\mathrm{i}}$, sehingga:

Beban vertikal:

$q u=c . N c . s c \cdot d c+D f \cdot \gamma \cdot N q \cdot S q \cdot d q+0,5 \cdot \gamma \cdot B \cdot N \gamma$.

$s \gamma \cdot d q$

Beban miring:

$q u=c . N c . s c . d c . i c+D f \cdot \gamma \cdot N q . d q . i q+0,5 \cdot \gamma \cdot B \cdot N \gamma$.

$d \gamma . i \gamma$

$s c, s q, s \gamma=$ faktor bentuk fondasi

$d c, d q, d \gamma=$ faktor kedalaman fondasi

$i c, i q, i \gamma \quad=$ faktor kemiringan

\section{Kajian Penelitian Terdahulu}

Martini (2009) melakukan penelitian Analisis Daya Dukung Tanah Fondasi Dangkal Dengan Beberapa Metode. Penelitian ini bertujuan untuk mendapatkan nilai daya dukung tanah berdasarkan metode Terzaghi, Meyerhof, Hansen, Vesic dan Oshaki.

Daya dukung tanah pada fondasi dengan beban sentris diperoleh hasil bahwa sebaiknya yang digunakan metode Terzaghi karena selain rumusnya yang sederhana, nilai daya dukung tanah yang relatif lebih kecil dibanding metode yang lain, sehingga dapat dikatakan lebih aman. Untuk beban miring sebaiknya digunakan perhitungan daya dukung tanah pada fondasi dangkal dengan metode Meyerhof karena memperoleh nilai daya dukung tanah yang relatif lebih stabil kenaikannya yaitu semakin besar lebar fondasi maka semakin besar pula daya dukungnya.

Anwar Muda (2016) Melakukan penelitian Analisis Daya Dukung Tanah Fondasi Dangkal Berdasarkan Data Laboratorium. Penelitian ini bertujuan untuk Mengetahui nilai daya dukung tanah fondasi dangkal dengan metode Terzaghi, Meyerhof.

Hasil penelitian menunjukan bahwa daya dukung tanah ultimate fondasi dangkal metode Meyerhof lebih besar dibanding dengan metode Terzaghi. Jika dilihat dari besaran daya dukung tanah 
ultimate fondasi dangkal, maka daya dukung tanah ultimate metode Meyerhof naik rata-rata sebesar $54.82 \%$ dibandingkan dengan metode Terzaghi.

\section{METODE PENELITIAN}

\section{Penyelidikan Hand Boring}

Penyelidikan tanah menggunakan metode ini bertujuan menentukan jenis dan sifat-sifat tanah (soil properties) pada lokasi yang akan dibangun fondasi dari tiap tebal lapisannya. Pengambilan sampel tanah ini dikenal dengan sebutan undisturbed soil sample (pengambilan tanah tidak terganggu). Pengambilan sampel tanah ini adalah dengan cara mengebor kedalam tanah sampai kedalaman tertentu dengan menggunakan tabung (pipa) logam berongga.

\section{Sifat Fisik Tanah}

Tanah dalam keadaan alami atau asli memiliki beberapa sifat-sifat dasar. Sifat-sifat dasar tersebut berupa sifat fisik yang berhubungan dengan tampilan dan ciri-ciri umum dari tanah. Sifat fisik tanah untuk mengetahui jenis tanah tersebut. Pada penelitian ini pengujian sifat fisik tanah meliputi:

1. Pemeriksaan Kadar Air (Water Content)

2. Pemeriksaan Berat Volume (Unit Weight)

3. Pemeriksaan Berat Jenis (Specific Test)

4. Pemeriksaan Batas-batas (Atterberg)

5. Pemeriksaan Analisis Saringan ( Sieve Analysis)

\section{Sifat Mekanik Tanah}

Sifat mekanik tanah merupakan sifat perilaku dari struktur massa tanah pada saat dikenai suatu gaya atau tekanan yang dijelaskan secara teknik mekanik.

Sifat mekanik dalam penelitian ini menggunakan pengujian direct shear, yang dimana bertujuan untuk menentukan parameter kuat geser tanah yaitu kohesi tanah (c) dan sudut geser dalam tanah $(\phi)$.

\section{Daya Dukung Tanah}

Dari hasil pengujian direct shear diperoleh data kohesi tanah (c) dan sudut geser dalam tanah $(\phi)$, maka selanjutnya dilakukan perhitungan daya dukung tanah fondasi dangkal berbentuk bujur sangkar. Adapun perhitungan daya dukung tanah fondasi dangkal dilakukan dengan metode Terzaghi dan Meyerhof.

\section{Desain Fondasi Telapak}

Desain fondasi harus mencakup segala aspek agar terjamin keamanan sesuai dengan persyaratan yang berlaku misalnya, penentuan dimensi fondasi yang meliputi panjang, lebar dan ketebalan fondasi. Pada penelitian ini dilakukan perhitungan daya dukung fondasi dan analisis terhadap daya dukung dengan metode Terzaghi dan Meyerhof. Adapun model fondasi yang dianalisis dapat dijelaskan pada Gambar 1 berikut ini:

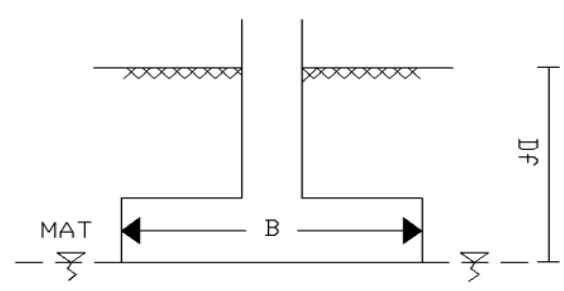

Gambar 1. Model Fondasi Telapak

\section{HASIL DAN PEMBAHASAN}

\section{Hasil Penelitian}

\section{Pengujian Sifat Fisik Tanah}

Sifat fisik tanah pada penelitian ini dapat di lihat pada Tabel 1 di bawah ini:

Tabel 1. Hasil Pengujian Sifat Fisik Tanah

\begin{tabular}{llc}
\hline No & Jenis Pemeriksaan & Nilai \\
\hline 1 & Kadar Air & 40,53 \\
2 & Berat Isi & 1,38 \\
3 & Berat Jenis & 2,72 \\
4 & Batas-Batas (Atterberg) & \\
& LL \% & 47,13 \\
& PL \% & 35,42 \\
& PI \% & 23,52 \\
& SL \% & 26,57 \\
5 & Analisa Saringan & \\
& Persentase Berat & \\
& Tertahan saringan & 48,84 \\
& No.200 (\%) & \\
& Persentase Lolos & 51,16 \\
& No.200 (\%)
\end{tabular}

Sumber : Hasil Perhitungan (2021) 


\section{Analisis Sifat Fisik Tanah}

Berdasarkan dari hasil presentase lolos analisis saringan nomor 200 sebesar 51,16\%,batas cair sebesar 47,13 \%, Indeks Plastisitas (IP) sebesar 23,52\%, maka hasil klasifikasi tanah dari tabel AASHTO yang diuji adalah tanah berlempung dengan kondisi sedang sampai buruk dan termasuk dalam klasifikasi kelompok A-7-6(14).

\section{Pengujian Sifat Mekanik Tanah}

Sifat mekanik tanah dapat dilihat pada Tabel 2 berikut ini:

Tabel 2. Sifat Mekanik Tanah

\begin{tabular}{lcc}
\hline Jenis Pemeriksaan & Satuan & Nilai \\
\hline Kohesi $(\mathrm{c})$ & $\mathrm{kg} / \mathrm{cm}^{2}$ & 0,192 \\
Sudut geser dalam $(\phi)$ & $\circ$ & 27 \\
\hline
\end{tabular}

Sumber : Hasil Perhitungan (2021)

\section{Daya Dukung Fondasi Dangkal}

Penelitian ini membandingkan nilai daya dukung tanah fondasi dangkal menggunakan metode Terzaghi dan Meyerhof

Data yang digunakan:

$$
\begin{aligned}
& \gamma=13,533 \mathrm{KN} / \mathrm{m}^{3} \\
& \gamma^{\prime}=\gamma_{\text {sat }}-\gamma_{w} \\
& \gamma^{\prime}=13,533-9,81=3,723 \mathrm{KN} / \mathrm{m}^{3} \\
& D f=1,5 \mathrm{~m} \\
& B=1,2 \mathrm{~m} \\
& c=0,192 \mathrm{~kg} / \mathrm{m}^{2} \\
& \phi=27^{\circ}
\end{aligned}
$$

Penyelesaian:

\section{Metode Terzaghi}

Untuk $\phi=27^{\circ}$, berdasarakan tabel faktor daya dukung Terzaghi, dengan asumsi terjadi keruntuhan geser umum, sehingga di dapatkan:

$$
\begin{aligned}
& N_{c}=29,24 ; N_{q}=15,90 ; N_{\gamma}=11,60 \\
& q u=1,3 \cdot c \cdot N_{c}+q \cdot N_{q}+0,4 \cdot \gamma^{\prime} \cdot B \cdot N_{\gamma} \\
& q u=1,3 \times 18,858 \times 29,24+(1,5 \times 13,533) \times 15,90+ \\
& 0,4 \times 3,723 \times 1,2 \times 11,60 \\
& q u=1060,330 \mathrm{KN} / \mathrm{m}^{3}
\end{aligned}
$$

Angka keamanan kita ambil nilai Fs $=3$, maka:

$$
\begin{aligned}
& q u_{i j i n}=\frac{q u}{f_{s}} \\
& q u_{i j i n}=\frac{1060,330}{3} \\
& q u_{i j i n}=353,443 \mathrm{KN} / \mathrm{m}^{3}
\end{aligned}
$$

\section{Metode Meyerhof}

Untuk $\phi=27^{\circ}$, di dapatkan berdasarakan tabel faktor daya dukung Meyerhof, didapatkan nilai: $N_{c}=13,199 ; N_{q}=23,942 ; N_{\gamma}=14,47$

Faktor bentuk, untuk $\emptyset>10^{\circ}$ :

$$
\begin{aligned}
& \mathrm{S}_{\mathrm{c}}=1+0,2 \times \frac{B}{L} \tan ^{2}\left(45+\frac{\phi}{2}\right) \\
& \mathrm{S}_{\mathrm{c}}=1+0,2 \times \frac{1,2}{1,2} \tan ^{2}\left(45+\frac{27}{2}\right) \\
& \mathrm{S}_{\mathrm{c}}=1,533 \\
& \mathrm{~S}_{\mathrm{q}}=F_{S \gamma}=1+0,1 \times \frac{B}{L} \tan ^{2}\left(45+\frac{\phi}{2}\right) \\
& \mathrm{S}_{\mathrm{q}}=F_{s \gamma}=1+0,1 \times \frac{1,2}{1,2} \tan ^{2}\left(45+\frac{27}{2}\right) \\
& \mathrm{S}_{\mathrm{q}}=F_{s \gamma}=1,266
\end{aligned}
$$

Faktor kedalaman, untuk $\emptyset>10^{\circ}$ :

$$
\begin{aligned}
& \mathrm{d}_{\mathrm{c}}=1+0,2 \times \frac{D f}{L} \tan ^{2}\left(45+\frac{\phi}{2}\right) \\
& \mathrm{d}_{\mathrm{c}}=1+0,2 \times \frac{1,5}{1,2} \tan ^{2}\left(45+\frac{27}{2}\right) \\
& \mathrm{d}_{\mathrm{c}}=1,666 \\
& \mathrm{~d}_{\mathrm{d}}=F_{\gamma d}=1+0,1 \frac{D f}{B} \tan ^{2}\left(45+\frac{\phi}{2}\right) \\
& \mathrm{d}_{\mathrm{d}}=F_{\gamma d}=1+0,1 \frac{1,5}{1,2} \tan ^{2}\left(45+\frac{27}{2}\right) \\
& \mathrm{d}_{\mathrm{d}}=F_{\gamma d}=1,333 \\
& \mathrm{qu}=\mathrm{c} \cdot \mathrm{N}_{\mathrm{c}} \cdot \mathrm{s}_{\mathrm{c}} \cdot \mathrm{d}_{\mathrm{c}}+\mathrm{D}_{\mathrm{f}} \cdot \gamma \cdot \mathrm{N}_{\mathrm{q}} \cdot \mathrm{s}_{\mathrm{q}} \cdot \mathrm{d}_{\mathrm{q}}+0,5 \cdot \gamma \cdot \mathrm{B} \cdot \mathrm{N} \gamma \cdot \mathrm{s} \gamma \cdot \mathrm{d}_{\mathrm{q}} \\
& q u=(18,858 \times 23,942 \times 1,533 \times 1,666)+(1,5 \times 13,533 \times \\
& 13,199 \times 1,266 \times 1,333)+(0,5 \times 13,533 \times 1,2 \times 14,47 \times \\
& 1,266 \times 1,333) \\
& \mathrm{qu}=1803,554 \mathrm{KN} / \mathrm{m}^{2}
\end{aligned}
$$

Angka keamanan kita ambil nilai $\mathrm{Fs}=3$, maka: 


$$
\begin{aligned}
q u_{i j i n} & =\frac{q u}{f_{s}} \\
q u_{i j i n} & =\frac{1803,554}{3} \\
q u_{i j i n} & =601,185 \mathrm{KN} / \mathrm{m}^{2}
\end{aligned}
$$

Berdasarkan perhitungan analisis daya dukung tanah fondasi dangkal metode Terzaghi dan Meyerhof di dapatkan hasil rekapitulasi seperti pada Tabel 2 di bawah ini:

Tabel 2. Hasil Analisis Daya Dukung Tanah

\begin{tabular}{lll}
\hline Metode & Satuan & Nilai \\
\hline Terzaghi & $\mathrm{KN} / \mathrm{m}^{2}$ & 353,443 \\
Meyerhof & $\mathrm{KN} / \mathrm{m}^{2}$ & 601,185 \\
\hline
\end{tabular}

Sumber : Hasil Perhitungan (2021)

Berdasarkan pada Tabel di atas menunjukan metode Terzaghi lebih kecil nilainya dibandingkan dengan metode Meyehof.

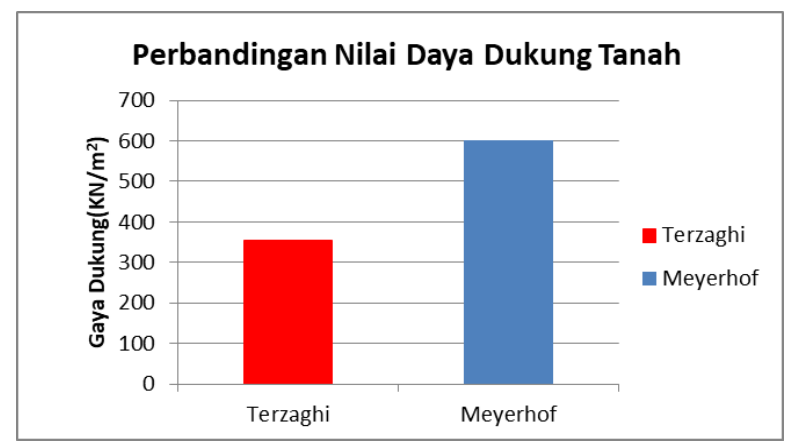

Gambar 2. Grafik Perbandingan Nilai Daya Dukung Tanah

\section{PENUTUP}

\section{Kesimpulan}

Hasil perhitungan daya dukung tanah fondasi bujur sangkar menunjukan metode Terzaghi lebih kecil nilainya dibandingkan dengan metode Meyehof. Dari Metode Terzaghi ke metode Meyerhof memiliki kenaikan sebesar 70,094 \%. Di karenakan metode Terzaghi mengasumsikan bahwa zona tekanan aktif di bawah dasar fondasi mempunyai sudut sama dengan sudut geser $\varnothing$, sedangkan Meyerhof mengasumsikan bahwa zone tekanan aktif mempunyai sudut serupa dengan tekanan aktif Rankine $(45+\phi / 2)$.

\section{Saran}

Berdasarkan kesimpulan di atas, maka perlu disarankan sebagai berikut :

1. Daya dukung tanah fondasi dangkal berdasarkan penyelidikan hand boring perlu dilakukan pembanding dengan penyelidikan tanah menggunakan metode sondir dan metode lainnya.

2. Untuk penelitian lebih lanjut dapat digunakkan jenis tanah yang berbeda agar dapat membandingkan nilai daya dukung tanah tersebut.

3. Daya dukung tanah fondasi dangkal perlu di bandingkan dengan metode lainnya seperti metode Hansen dan Vesic.

\section{DAFTAR PUSTAKA}

Bowles, J. E. (1997). Analisis dan Desain Pondasi, Jilid 1 Edisi 4. Erlangga: Jakarta.

Hakam, A. (2008). Rekayasa Pondasi. Bintang Grafika: Padang.

Hardiyatmo, C. H. (2002). Mekanika Tanah II. Gajah Mada University Press: Yogyakarta.

Hardiyatmo, C. H. (1996). Teknik Fondasi I. Gramedia Pustaka Utama: Jakarta.

Martini. (2009). Analisis Daya Dukung Tanah Pondasi Dangkal Dengan Beberapa Metode. Majalah Ilmiah Mektek Tahun, 11(2), pp.75-87.

Muda, A. (2016). Analisis Daya Dukung Tanah Fondasi Dangkal Berdasarkan Data Laboratorium. Jurnal ITEKNA, 16(1), pp.1100. 